\title{
PENGGUNAAN TEKNIK BRAINWRITING DALAM MENULIS CERITA ANAK DI TK AL BIRUNI DAN TK KHOIRU WA ABQO
}

\author{
Hilda Hilaliyah ${ }^{1)}$, Yulia Agustin'), Siti Muharomah ${ }^{3)}$ \\ ${ }^{1,2,3}$ Program Studi Pendidikan Bahasa Indonesia \\ Fakultas Bahasa dan Seni, Universitas Indraprasta PGRI
}

\begin{abstract}
Abstrak
Dalam meningkatkan keterampilan menulis cerita anak, dibutuhkan teknik yang tepat. Satu di antaranya adalah teknik brainwriting. Teknik ini merupakan salah satu alternatif yang dapat dimanfaatkan dalam proses pembelajaran menulis cerita anak. Teknik brainwriting bertujuan mencurahkan gagasan tentang suatu pokok permasalahan yang dilakukan secara tertulis. Sesuai dengan fungsinya, teknik brainwriting dapat memotivasi seseorang untuk memunculkan banyak ide dalam menulis cerita anak. Berdasarkan hasil observasi awal, didapati bahwa para guru di TK Al Biruni dan TK Khoiru Wa Abqo kesulitan dalam meningkatkan keterampilan menulis. Hal ini disebabkan oleh kurangnya pelatihanpelatihan menulis, seperti brainwriting yang mengandalkan kreativitas guru. Berdasarkan hasil pengabdian kepada masyarakat yang dilakukan, dapat disimpulkan bahwa penerapan teknik brainwriting dalam mengembangkan dan meningkatkan keterampilan para guru TK dalam menulis cerita anak sangat penting dilatih. Penerapan teknik brainwriting dilakukan agar para guru dapat menulis buku cerita sendiri yang disesuaikan dengan bahan ajar dan mempunyai nilai edukatif untuk peserta didik TK.
\end{abstract}

Kata kunci: teknik brainwriting, menulis cerita anak, para guru

\begin{abstract}
In improving children's story writing skills, the right techniques are needed. One of them is brainwriting technique. This technique is one alternative that can be utilized in the learning process of writing children's stories. Brainwriting techniques aim to devote ideas about a subject matter that is done in writing. In accordance with its function, brainwriting techniques can motivate someone to come up with many ideas in writing children's stories. Based on the results of preliminary observations, it was found that teachers at TK Al Biruni and TK Khoiru Wa Abqo had difficulty in improving writing skills. This is caused by a lack of writing training, such as brainwriting that relies on teacher creativity. Based on the results of community service done, it can be concluded that the application of brainwriting methods in developing and improving the skills of kindergarten teachers in writing children's stories is very important to be trained. The application of brainwriting methods is done so that teachers can write their own storybooks that are adapted to teaching materials and have educational value for kindergarten students.
\end{abstract}

Keywords: brainwriting technique, writing children's stories, teachers

Correspondence author: Hilda Hilaliyah, hilda.unindra@gmail.com, Jakarta, Indonesia.

This work is licensed under a CC-BY-NC 


\section{PENDAHULUAN}

Untuk menghasilkan proses belajar mengajar yang baik, salah satu faktor pendukungnya adalah peran seorang guru. Seorang guru harus berusaha mengembangkan ilmu dan konsep pembelajaran di kelas bagi peserta didiknya. Dalam proses pembelajaran, kegiatan belajar mengajar merupakan hal yang sangat penting untuk mengetahui berhasil atau tidaknya suatu pembelajaran, sehingga ketika proses belajar berlangsung pemeran utama yaitu guru profesional.

Ciri-ciri kematangan profesional guru yaitu memiliki: (1) keahlian, (2) rasa tanggung jawab, dan (3) rasa kesejawatan yang tinggi. (Mariyana, 2014: 7). Guru profesional prasekolah (PAUD) dan guru TK harus memiliki berbagai keterampilan. Adapun Janice Beaty dalam Mariyana (2007: 11) mengemukakan beberapa jenis keterampilan untuk guru pendidikan prasekolah (PAUD) dan guru TK termasuk di dalamnya, yaitu : (1) Memelihara keselamatan kelas (Maintaining a safe a classroom), (2) Memelihara kesehatan kelas (Maintaining a healthy classroom), (3) Membangun lingkungan belajar (Establishing a learning environment), (4) Meningkatkan Keterampilan fisik (Advancing physical skills), (5) Meningkatkan Keterampilan komunikasi (Advancing communication skills), (6) Meningkatkan Keterampilan kreativitas (Advancing creative skills), (7) Menumbuhkan konsep diri positif (Building a positive self-concept), (8) Memperkenalkan keterampilan sosial (Promoting social skills), (9) Menyediakan bimbingan penyuluhan (Providing guidance), (10) Memperkenalkan peran serta keluarga (Promoting family involvement), (11) Menyediakan pengelolaan program (Providing program management), (12) Menanamkan sikap profesionalisme (Promoting professionalism)

Berkaitan dengan hal tersebut, salah satu keterampilan yang perlu ditingkatkan yaitu keterampilan kreativitas (creative skills). Keterampilan kreativitas ini dapat dicapai melalui keterampilan bercerita dan keterampilan menulis. Keterampilan bercerita adalah cara menyampaikan nilai-nilai kebaikan dan cerita yang disajikan pun bernuansa ceria, gembira, lucu, dan mudah dimengerti (Permana, Hilaliyah, \& Jubei, 2009: 188), sedangkan keterampilan menulis merupakan keterampilan menyampaikan pesan (komunikasi) dengan menggunakan bahasa tulis sebagai alat atau medianya (Suparno \& Yunus dalam Kurniadi, Hilaliyah, \& Rosadi, 2018: 232).

Pada dasarnya kemampuan menulis sangat diperlukan dalam kehidupan nyata. Misalnya menulis untuk berbagai macam tulisan, baik fiksi dan nonfiksi atau menulis ilmiah dan non ilmiah. Oleh karena itu, kemampuan menulis yang baik sangatlah dibutuhkan bagi peserta didik dikemudian hari karena akan mampu memberikan kesempatan dan juga tantangan yang lebih bagi mereka.

Menulis merupakan suatu representasi bagian dari kesatuan-kesatuan ekspresi bahasa. Menulis sangat penting bagi pendidikan karena memudahkan para pelajar berpikir. Juga memudahkan kita merasakan daya tanggap atau persepsi kita, memecahkan masalah-masalah yang dihadapi, menyusun urutan bagi pengalaman. Hasil tulisan merupakan satu-satunya media untuk menyampaikan pesan yang ingin kita sampaikan. Menulis juga merupakan keterampilan peserta didik yang bermula dari perasaan, maka dengan menyentuh perasaanya dan representasi dari perasaan adalah bentuk ekspresif dan imajinasi (sastra). Dalam kehidupan modern ini jelas bahwa keterampilan menulis sangat dibutuhkan untuk segala keperluan. Keterampilan menulis merupakan suatu ciri dari orang yang terpelajar atau bangsa yang terpelajar (Tarigan dalam Azizah, 2015: 137). 
Keterampilan menulis perlu dikuasai oleh para guru. Guru yang terampil menulis tentu nantinya diharapkan dapat juga membimbing peserta didiknya untuk terampil menulis juga. Dengan catatan, keterampilan menulis tersebut diajarkan dengan cara dan teknik yang menyenangkan. Peserta didik selayaknya dikondisikan agar tidak merasa terbebani dan tertekan. Salah satu teknik menulis yang sangat menarik dan saat ini sedang berkembang adalah teknik brainwriting.

Brainwriting adalah menulis segala sesuatu yang terlintas di otak. Teknik Brainwriting merupakan teknik untuk mencurahkan gagasan tentang suatu pokok permasalahan atau tentang suatu hal secara tertulis yang dikembangkan oleh Ilmuwan di Batelle Institute di Frankfurt, Jerman (Michalko, 2004). Teknik tersebut merupakan teknik curah-gagasan yang dilakukan secara tertulis.

Dalam menulis cerita anak dibutuhkan strategi atau teknik yang dapat mempermudah guru dalam proses pembelajaran dan mempermudah guru dalam menyampaikan materi kepada peserta didik. Dalam hal ini teknik brainwriting merupakan salah satu alternatif teknik yang dapat dimanfaatkan dalam proses pembelajaran menulis cerita anak. Teknik brainwriting bertujuan mencurahkan gagasan tentang suatu pokok permasalahan yang dilakukan secara tertulis. Sesuai dengan fungsinya yaitu teknik brainwriting dapat memotivasi seseorang untuk memunculkan banyak ide untuk menulis cerita anak.

Berdasarkan uraian di atas, tim pelaksana yang berlatar belakang Pendidikan Bahasa Indonesia tertarik untuk melakukan kegiatan Iptek bagi Masyarakat pada guruguru TK dengan judul Penggunaan Teknik Brainwriting dalam Menulis Cerita Anak.

Sehubungan dengan uraian di atas, didapatkan data bahwa para guru yang berada di TK Al Biruni dan TK Khoiru Wa Abqo kesulitan dalam meningkatkan keterampilan menulis. Hal ini disebabkan oleh kurangnya pelatihan-pelatihan yang mengandalkan kreativitas guru. Kreativitas guru perlu ditingkatkan agar saat pelaksanaan pembelajaran, peserta didik dapat antusias dan merasa senang berada di sekolah. Selama ini, para guru tidak dilatih untuk mengembangkan kreativitas keterampilan menulis, terlebih lagi dalam hal menulis cerita anak. Dengan demikian, permasalahan yang terjadi pada proses meningkatkan keterampilan menulis adalah sebagai berikut: 1 . Para guru TK membutuhkan informasi dan motivasi agar lebih kreatif dalam mengembangkan keterampilan menulis. 2. Para guru TK mengalami kesulitan dalam mengembangkan keterampilan menulis cerita anak. 3. Para guru TK membutuhkan pelatihan menulis cerita anak dengan teknik brainwriting dan contoh penerapannya.

\section{METODE PELAKSANAAN}

Pelatihan ini diselenggarakan di dua Sekolah Taman Kanak-Kanak. Pertama di TK Al Biruni. TK ini terletak di Jalan H. Sabeni No.7 RT 007 RW 02, Kalisari, Pasar Rebo, Jakarta Timur. Kedua, di TK Khoiru Wa'Abqo yang terletak di Jalan KH Muhasan I RT 03/02, Kelurahan Meruyung, Kecamatan Limo, Kota Depok.

Kedua TK ini terpilih sebagai tempat pelatihan karena berdasarkan hasil observasi dan survei terhadap guru-guru TK, informasi yang didapat yaitu mereka sangat minim tentang keterampilan menulis, terlebih lagi dengan cerita anak. Selain itu, mereka belum pernah mengaplikasikan teknik brainwriting.

Teknik yang digunakan dalam pengabdian masyarakat ini adalah teknik ceramah plus yang dipadukan dengan diskusi, tanya-jawab, dan praktik. Selain itu, tim 
pelaksana melakukan pendampingan. Hal ini dimaksudkan agar pelatihan ini memberikan manfaat kepada semua pihak yang menjadi mitra abdimas tim.

Kegiatan pengabdian masyarakat ini dilaksanakan pada November-Desember 2017 hingga Januari 2018. Pada pengabdian masyarakat ini, tim mengundang narasumber yang mumpuni di bidang ini, yaitu Sumarti, M.Pd.. Beliau adalah praktisi yang aktif di bidang per-PAUD-an dan Kurikulumnya. Beliau mengupas tuntas materi teknik brainwriting dan aplikasinya.

Beberapa alat-alat yang digunakan untuk menunjang pengabdian kepada masyarakat ini disediakan oleh pihak mitra dan beberapa disediakan oleh pihak tim. Alat- alat yang disediakan oleh pihak mitra adalah proyektor dan laptop. Alat-alat yang disediakan oleh tim adalah buku tulis kecil, hand out pelatihan dan pendukung alat tulis lainnya.

Adapun kegiatan-kegiatan yang dilakukan, yaitu: Survei awal tempat pelaksanaan; Perizinan; Penentuan peserta; Pembuatan proposal dan penyelesaian administrasi perjanjian dengan mitra pengabdian masyarakat; Menyiapkan materi pelatihan. Kegiatan pengabdian ini dilaksanakan setelah semua perjanjian dan persiapan selesai dilakukan. Kegiatan ini dibuat menjadi beberapa pertemuan sehingga para guru TK dapat memahami materi pelatihan. Evaluasi bertujuan untuk melihat perkembangan program yang dilaksanakan. Tim abdimas mengumpulkan hasil pelatihan untuk dilakukan pendampingan. Selain itu, evaluasi dilakukan untuk mengetahui kendala yang ada dan mencari cara menanganinya sehingga program pengabdian yang dilakukan benar-benar efektif dan maksimal. Laporan dibuat sebagai bentuk pertanggungjawaban tim terhadap kegiatan yang dilaksanakan. Tahapannya yaitu pelaporan awal, perevisian laporan, dan pelaporan akhir.

\section{HASIL DAN PEMBAHASAN}

Menulis ialah keterampilan mengeluarkan, mengekspresikan isi hati dalam bentuk tulisan. Keterampilan ini erat sekali hubungannya dengan keterampilan bahasa yang lain, yaitu keterampilan membaca, keterampilan menyimak, dan keterampilan berbicara. Bagi anak usia dini, menulis merupakan bagian dari proses perkembangannya dalam memperoleh dan belajar bahasa. Berkaitan dengan belajar anak, seorang guru harus mengetahui perkembangan otak anak sebagaimana tampak pada diagram berikut (Sumarti, dkk. 2016: 157).

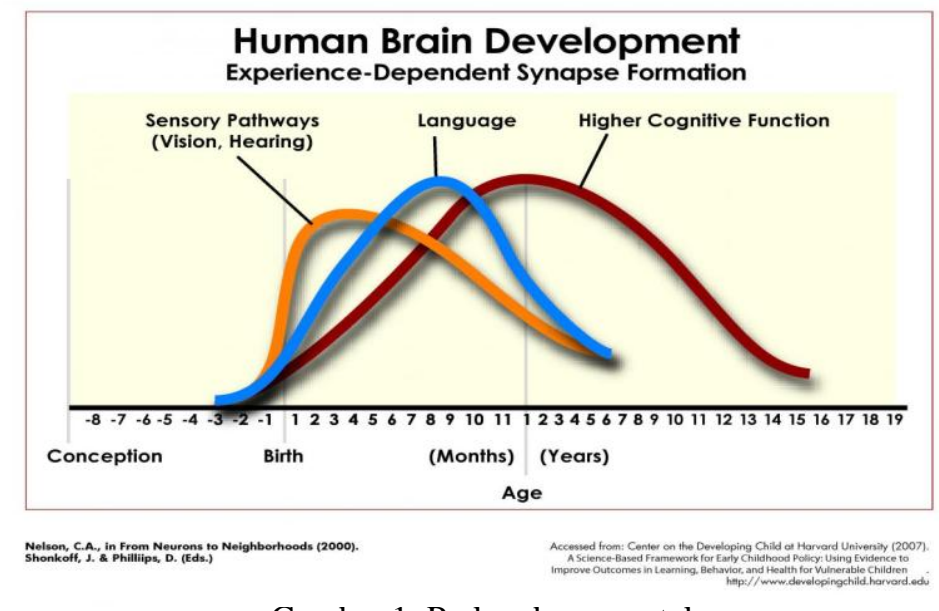

Gambar 1. Perkembangan otak 
Berdasarkan diagram tersebut tampak bahwa perkembangan bahasa terjadi bersamaan dengan perkembangan gerak dan kognitif. Dapat disimpulkan bahwa teknik Brainwriting merupakan teknik untuk mencurahkan gagasan tentang suatu pokok permasalahan atau tentang suatu hal secara tertulis. Dengan kata lain. Brainwriting adalah menulis segala sesuatu yang terlintas di otak.

Darmadi (Azizah, 2015: 138) ada dua prinsip penting yang harus diingat di dalam melakukan brainwriting. Pertama, jangan memikirkan ide yang dihasilkan itu benar atau salah, yang penting di dalam prosesi ini adalah pengumpulan ide-ide yang berkaitan dengan topik sebanyak-banyaknya. Kedua, terjadinya tumpang tindih ide dianggap sebagai suatu yang wajar karena memang belum dievaluasi. Dengan demikian proses ini adalah secara sadar atau tidak kita telah memulai proses berpikir. Rangkaian proses berpikir seperti ini akan membangkitkan kemampuan intelektual yang dimiliki seseorang. Jadi, proses berpikir itu dilakukan secara berkesinambungan sehingga rangkaian proses ini dapat menghasilkan ide-ide yang lebih menarik daripada ide awalnya.

\section{TK Al Biruni}

Pelatihan penggunaan teknik brainwriting dalam menulis cerita anak di TK al Biruni terletak di Jalan H. Sabeni No.7 RT 007/02 Kalisari, Pasar Rebo Jakarta Timur. Pelatihan ini terbagi menjadi 2 tahapan, yaitu Tahapan pertama yaitu penjelasan materi brainwriting dan tahap kedua yaitu praktik membuat kreativitas menulis cerita anak dengan teknik brainwriting.

Adapun materi pelatihan yang diberikan tentang: Keterampilan kreativitas (creative skill): Kreativitas keterampilan ini dapat dicapai melalui keterampilan menullis; Teknik Brainwriting. Teknik ini adalah sebuah teknik pembelajaran yang cara penyampaiannya melalui sebuah tulisan atau tertulis. Teknik brainwriting merupakan teknik untuk mencurahkan gagasan tentang suatu pokok permasalahan atau tentang suatu hal secara tertulis.

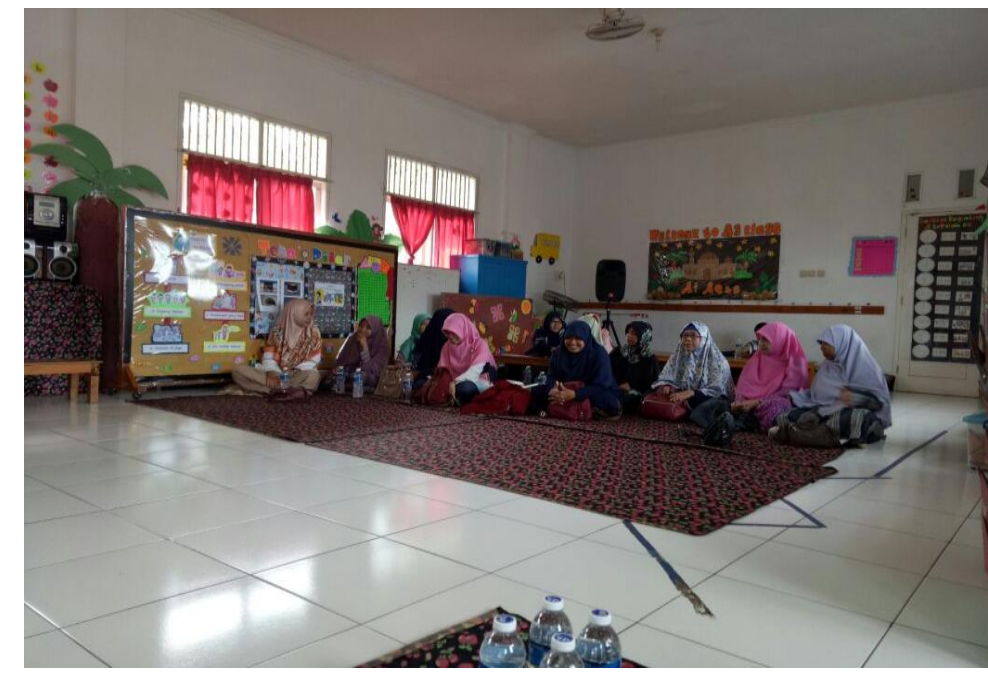

Gambar 2. Para guru, peserta pengabdian kepada masyarakat

Hasil yang dicapai dengan diadakannya pelatihan penggunaan Brainwriting dalam menulis cerita anak pada guru-guru di TK al Biruni adalah: 1. Para guru-guru TK al Biruni memahami teknik brainwriting dalam menulis cerita anak. 2. Para guru-guru TK 
al Biruni dapat mengembangkan kreativitas dalam menulis cerita anak. 3. Para guruguru TK al Biruni dapat membuat cerita anak yang inovatif yang bisa langsung diterapkan untuk proses pembelajaran. 4. Para guru-guru TK al Biruni dapat lebih tertantang dalam menciptakan kreativitas untuk bahan ajar peserta didik di kelas.

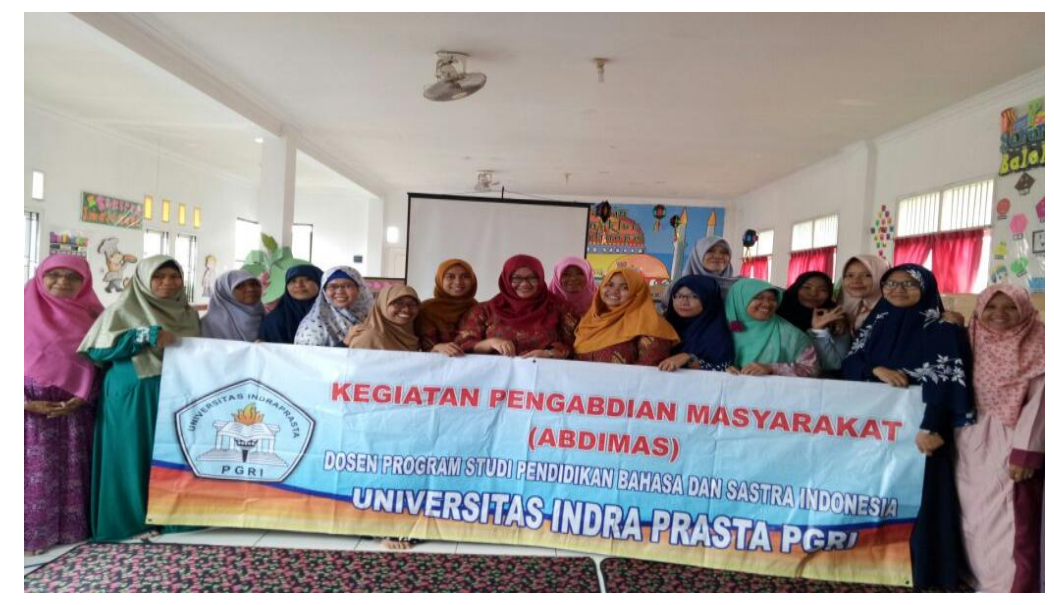

Gambar 3. Foto bersama tim dan peserta pengabdian kepada masyarakat

\section{TK Khoiru Wa'Abqo}

Pelatihan penggunaan teknik brainwriting dalam menulis cerita anak di TK Khoiru Wa'Abqo yang terletak di Jalan KH Muhasan I RT 03/02, Kelurahan Meruyung, Kecamatan Limo, Kota Depok. Pelatihan ini tidak berbeda tahapannya dengan yang di lakukan di TK Al Biruni. Kegiatan ini dibagi menjadi 2 tahapan, yaitu penjelasan materi brainwriting dan praktik membuat kreativitas menulis cerita anak dengan teknik brainwriting.

Adapun materi pelatihan yang diberikan pun sama, yaitu tentang: Keterampilan kreativitas (creative skill); Teknik Brainwriting; Praktik Penerapan Teknik Brainwriting

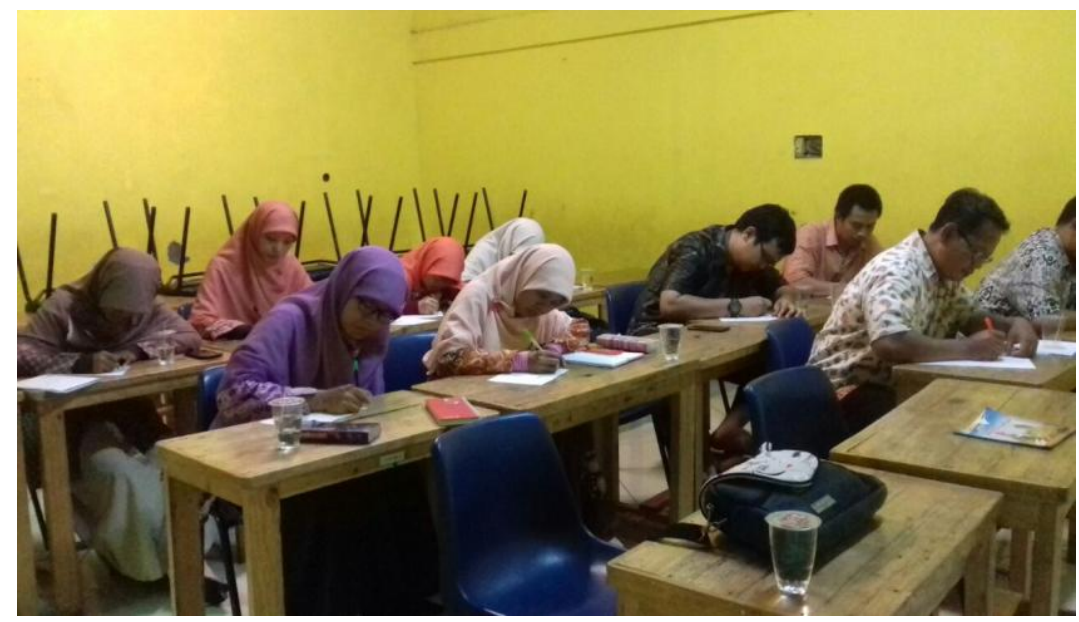

Gambar 4. Para peserta pelatihan sedang berlatih membuat cerita anak dengan teknik brainwriting

Hasil yang dicapai dari kegiatan abdimas ini, antara lain: Peserta antusias dengan datang tepat waktu; Peserta dapat mengikuti dengan tertib; Peserta aktif bertanya tentang masalah yang berkaitan dengan brainwriting dan menulis cerita anak; Peserta 
semangat praktik menulis cerita anak secara berkelompok sesuai dengan tema yang dipilih.

Berdasarkan hasil kegiatan yang telah dilakukan di kedua tempat dapat dikatakan bahwa kegiatan pengabdian kepada masyarakat ini berhasil. Hal ini tampak pada respons yang diberikan para peserta pelatihan dan karya sederhana yang dihasilkan. Pihak sekolah pun menginginkan kepada tim untuk mengadakan kegiatan lanjutan dalam tema yang berbeda dengan mengacu pada cara menyukseskan proses pembelajaran Luaran yang dihasilkan dalam dari pelaksanaan pelatihan ini, yaitu Hasil karya sederhana guru-guru (kumpulan cerita anak) dan artikel publikasi hasil pengabdian kepada masyarakat.

\section{SIMPULAN}

Berdasarkan hasil pengabdian kepada masyarakat yang dilakukan, dapat disimpulkan bahwa penerapan teknik brainwriting dalam rangka mengembangkan dan meningkatkan keterampilan para guru TK dalam menulis cerita anak sangat penting dilatih. Penerapan teknik brainwriting dilakukan agar para guru dapat menulis buku cerita sendiri yang disesuaikan dengan bahan ajar dan mempunyai nilai edukatif untuk peserta didik TK. Kegiatan ini dapat dikatakan berhasil karena dapat memberikan informasi dan motivasi kepada para guru di TK al Biruni dan TK Khoiru Wa Abqo agar lebih kreatif dalam mengembangkan kreativitasnya untuk menulis cerita anak. Selain itu, hasil pelatihan ini memberikan stimulus kepada para guru tentang cara meningkatkan kreativitas melalui keterampilan menulis. Tidak hanya itu, dengan adanya pelatihan menulis cerita anak melalui teknik Brainwriting, para guru TK dapat membuat buku cerita anak sendiri sebagai bahan ajar.

Berdasarkan simpulan di atas, saran-saran yang dapat diberikan adalah sebagai berikut: 1 . Kegiatan pelatihan ini perlu dilakukan secara kontinyu agar para guru dapat terus meningkatkan kreativitas diri dalam mengajar. 2. Perlu diadakan kegiatan lanjutan terkait dengan penerapan teknik-teknik dalam pembelajaran.

\section{DAFTAR PUSTAKA}

Azizah, A. (2015). Pembelajaran Menulis Puisi dengan Memanfaatkan Teknik Brainwriting pada Peserta Didik SD/MI Kelas V. Jurnal Ilmiah Pendidikan Dasar Vol. II No.2 Juli 2015, 137.

Kurniadi, F., Hilaliyah, H., \& Rosadi, N. (2018) Upaya Penguatan Pemahaman Menulis Deskripsi dan Narasi pada Penulisan Buku Laporan Hasil Belajar Siswa PAUD di Depok. Jurnal PkM Pengabdian kepada Masyarakat, 1(03),231-237. https://journal.lppmunindra.ac.id/index.php/pkm/article/view/2669 diunduh 17 Februari 2020.

Mariyana, R. (2014). Kompetensi Profesional Guru TK.http://103.23.244.11/direktori/fip/jur._pgtk/197803082001122rita_mariyana/ kompetensi_profesional_guru_tk.pdf diunduh 6 Oktober 2017) 
Mariyana, R. (2007). Pengembangan Program Pembelajaran Berbasis Bimbingan di Taman Kanak-Kanak (Studi Deskriftif terhadap Kompetensi Guru TK di kota Bandung). Tesis pada PPS UPI : Tidak diterbitkan

Michalko, M. (2004). Permainan Berpikir (Thinkertoys). Bandung: Remaja Rosdakarya.

Permana, A., Hilaliyah, H., \& Jubei, S. (2019). Penerapan Metode Edutainment dan Story Telling pada Guru-Guru Taman Pendidikan Quran (TPQ) Natiqul Quran. Jurnal PkM Pengabdian kepada Masyarakat,2(03), 187-193. https://journal.lppmunindra.ac.id/index.php/pkm/article/view/3724/2749 diunduh 17 Februari 2020.

Sumarti, dkk (2016). Fonologi. Tangerang: Pustaka Mandiri. 